\title{
Analysis of Patent Technology Transfer in China
}

\section{Take Guangdong Province as an Example}

\author{
Zhi Liping ${ }^{1} \&$ Li Yanyan ${ }^{2}$ \\ ${ }^{1} \mathrm{Ph}$. D of School of Computer Science \& Information Engineering, Anyang Normal University, Anyang, China \\ ${ }^{2}$ M.A student of Anyang Normal University, Anyang, China \\ Correspondence: Zhi Liping, School of Computer Science \& Information Engineering, Anyang Normal University, \\ Anyang, China. Tel: 1-350-372-8754.
}

Received: November 21, 2018; Accepted: December 12, 2018; Published: December 17, 2018

The research is financed by the Henan Philosophy and Social Science Project (No. 2015CZH004) \& the Training Scheme for Young Key Teachers in Universities of Henan (No. 2016GGJS-123) \& the Key Project of Science and Technology Research of Education Department of Henan (No. 16A520040) \& the Humanities and Social Science Project of Education Department of Henan (No. 2019-ZZJH-479) \& the Soft Science of Intellectual Property Rights of Henan (No. 20190106013).

\begin{abstract}
Taking the status of China's patent technology transfer as the research goal, select the representative Guangdong Province as the research object, Using the incopat innovative intelligence platform as a data source, 157,178 related content were retrieved, And from patent technology transfer trends, technology ownership, applicants, geography, legal and operational status, patent agents and other aspects of analysis. Research shows that the development of China's patent technology transfer is strong, but there are some problems, in particular, the transfer of patent technology in research institutes and research institutions needs to be strengthened, and there is a large gap in regional patent technology transfer. Therefore, it is necessary to create a favorable environment for patent licensing and technology transfer and transformation policies, and actively guide the industrialization of patent technology in universities and research institutions, Strengthen the transfer of scientific and technological achievements to the market, train and expand the technical transfer of professional talents and so on, further promote the integrated development of science and technology and the economy, and accelerate the transformation of scientific and technological achievements into actual productivity. China's patent technology research has certain reference value for other countries.
\end{abstract}

Keywords: China, Guangdong, patent technology transfer, patent transfer, patent license

\section{Introduction}

Technology transfer is the act of technology owners transferring their production technology, sales technology or management technology and related rights to any third person in various forms. Patent technology transfer is one of the main contents of technology transfer, especially the transfer of patent technology from one region to another in a certain way. The transfer of patent technology has become one of the important forms to realize the industrialization of patent technology, and it is also the main way to improve the overall core competitiveness of enterprises. China is rich in innovative resources and well-developed infrastructure, especially in recent years, and is considered to be an important highland for technological innovation in the world. It is of great theoretical significance to choose the representative Guangdong Province to conduct research on the status quo and countermeasures of Chinese patent technology transfer.

\section{Data Sources and Patent Search}

The data source is the incoPat Technology Innovation Intelligence Platform 4.0 developed by Beijing Hexiang Intelligent Technology Co., Ltd., which includes more than 100 million patent data received by 105 countries, regions and organizations around the world. The official website is http://www.incopat.com. The reason for choosing this search platform is based on incoPat not only the comprehensive patent data, but also the registration and filing data of patent licenses and patent transfers of the State Intellectual Property Office. The data source is 
authoritative and fast, which provides high-quality basic data for the study of patent technology transfer. This study searches and analyzes the patent technology transfer data of Guangdong Province in 1998-2017 on the incoPat innovation intelligence platform. The patent technology transfer mainly includes two forms of patent transfer and patent license.

Next, in the incoPat patent search system, the Guangdong province patent whose legal status is transfer or license is retrieved. The national code 44 represents Guangdong Province, and the final patent search formula is:

$((((($ ASSIGN-FLAG=1)OR(LICENCE-

FLAG=1)))AND((PNC=CNANDPT=("1"))OR(PNC=CNANDPT=("2"))OR(PNC=CNANDPT=("3"))))AND((P

$\mathrm{NC}=\mathrm{CNANDPT}=(" 1 ")) \mathrm{OR}(\mathrm{PNC}=\mathrm{CNANDPT}=(" 2 ")) \mathrm{OR}(\mathrm{PNC}=\mathrm{CNANDPT}=(" 3 ")))$ AND $(\mathrm{pnc}=\mathrm{cn})$ ANDAP$\mathrm{PC}=(" 44 ")$

\section{Data Analysis of Chinese Patent Technology Transfer}

\subsection{Overview}

The incopat data platform retrieves the total amount of patent technology transfer in 31 provinces across the country. The chart shows the top ten patent technology transfer volumes in China's provinces and cities, from which it can be analyzed: Guangdong Province ranks first in the country with 124,471 patents, and has a significant lead with Zhejiang, Jiangsu, Beijing, Shandong and other cities, but it is a big gap with cities such as Fujian, Sichuan, Hunan and Anhui. The reason for this is closely related to Guangdong's policy support. Due to the hightech enterprises in Guangdong, the corporate culture is strong, and the top management of the company actively encourages the transfer of patent technology and other factors.

Figure 1 can grasp the change of patent application heat in the analysis period from the macro level through the application trend. Since Guangdong Province is an open coastal city, after the reform, it is mainly based on manufacturing. This is also an early stage of industrial upgrading in Guangdong, that is, the transition from manufacturing to "creating" industries precedes inland areas. Therefore, the invention of patents in Guangdong has been increasing year by year. It is reflected in the statistics of the data. Before 2015, the number of patent applications and patent disclosures showed an increasing trend year by year, and reached the highest value in 2015 . Since the patented invention can only be made public until it is 18 months old, the data is statistically analyzed until 2015.

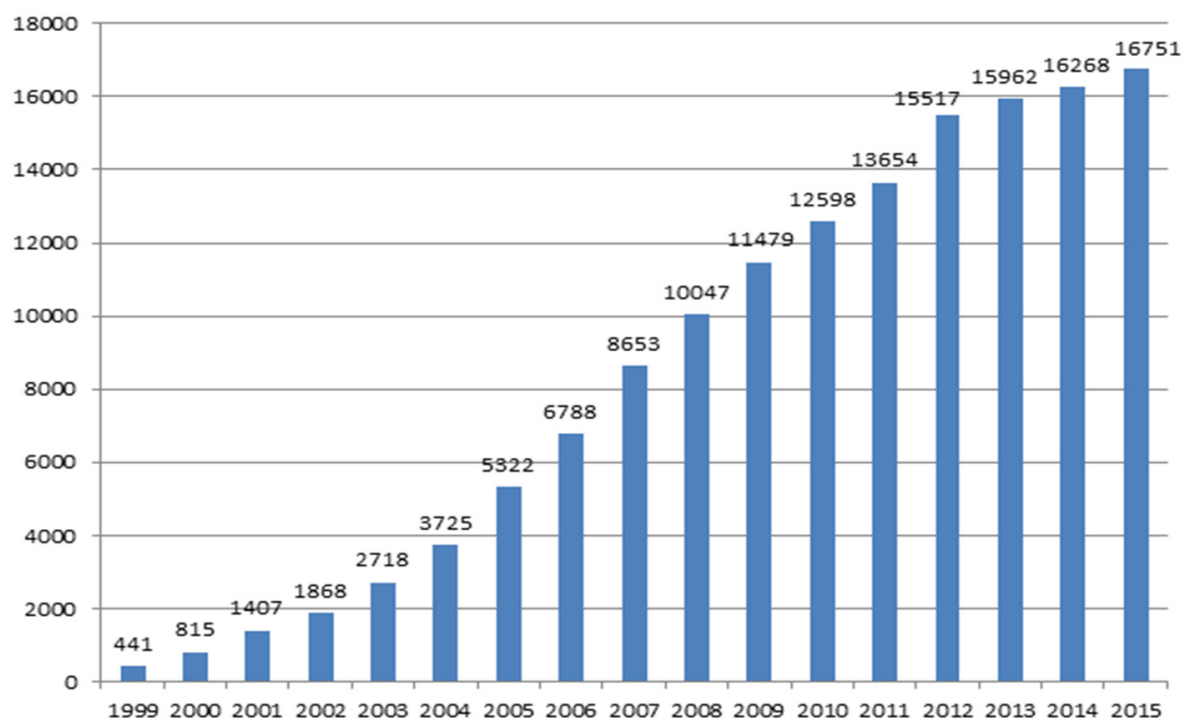

Figure 1. Development trend of patent application transfer in Guangdong Province (1999-2015)

\subsection{Analysis of IPC Technical Composition of Patent Technology Transfer}

The technical composition is represented by the IPC classification number. The top ten IPC classification numbers (in small categories) concluded: The main ones (such as G06F, F21V, H04L, and F21Y) involve high-tech industries such as electronic information, electronic equipment, and new materials, and there are areas such as A47J that are related to the daily life of the home. It is not difficult to see the comprehensiveness and diversity of the analytical objects in the technical components. According to the IPC classification number, the annual change 
trend of the technical composition of patent technology transfer in Guangdong Province is shown in Figure 1: The larger the bubble, the more patents there are. From the analysis in the figure, we can conclude that: H04W (wireless communication network) and H04L (transmission of digital information) continue to rise in number before 2008 ,and reached the highest peak around 2008, after which it decreased year by year. H21V (functional features or components of lighting fixtures or their systems; structural components of lighting fixtures and other items not included in other categories), G06F (electrical digital data processing), H21S (non-portable lighting fixtures or systems thereof) ), H21Y (involved in the composition of the light source combined with the subclass F21L, F21S and F21V), These four categories have increased significantly year after year after 2006, and the number of patent applications has increased by a large margin. Other classification topics such as H01R (conductive connection; a combination of structural components of mutually insulated electrical connection elements; connecting devices; current collectors), H05K (printed circuit; housing or structural parts of electrical equipment; manufacture of electrical component components), A47J (kitchenware; coffee mill; spice mill; beverage preparation device), H04N (image communication) did not change much. Therefore, Guangdong Province has gradually embarked on the development path of high-end industries, focusing on the development of the information and communication industry. This indicates that the current development of Guangdong Province is moving towards the matching of industrial layout and regional functions, and the direction of regional industrial dislocation and coordinated development.

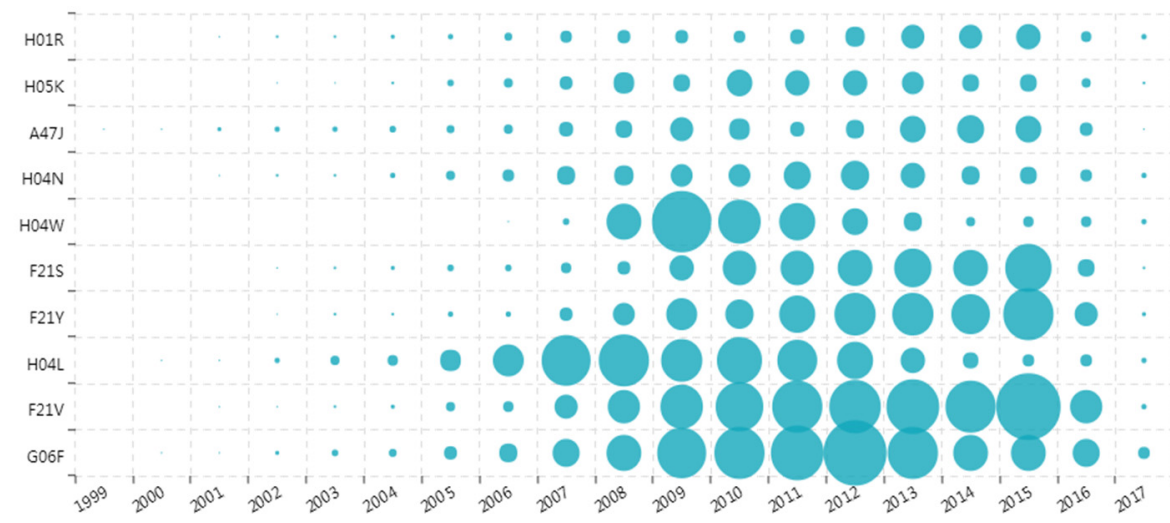

Figure 2. Distribution and development trend of patent applications in different technical directions (1999-2017)

\subsection{Analysis of Patent Transfer \& Patent Licensing}

According to statistics: Guangdong Province's patents are in the form of utility models, accounting for $44.34 \%$, invention and creation applications, accounting for $34.72 \%$, and accounting for $20.94 \%$ of the design . Since 2000 , Guangdong Province has developed rapidly in the direction of patent technology transfer, and the progress of patent licensing has been slow, with a large gap between the former and the former. Patent licenses are favored in other provinces and cities such as Beijing. This is because, on the one hand, patent licenses are flexible and flexible, including five types: full license, exclusive license, general license, sub-license, and cross-licensing; On the other hand, due to the good maturity of the patent license, the licensee can directly apply the patented technology to obtain greater benefits and returns in accordance with the contractual implementation permit method. Therefore, while promoting the development of patent transfer, Guangdong Province needs to recognize the advantages and importance of patent licensing and continuously strengthen the application of patent licensing.

\section{Research Conclusions and Recommendations}

According to the previous analysis of patent technology transfer trends, technology ownership, applicants, regions, legal and operational status, patent agents, etc., the research and analysis of the status quo and causes of patent technology transfer in Guangdong Province, the following conclusions and recommendations.

\subsection{Status and Existing Problems}

Patent is an important yardstick for regional creation level, and patent technology transfer is the main expression of patent industrialization. After analyzing this paper, we have learned that the main problems are: (1) The benefits of government technology investment to form technical patents are relatively low. (2) The geographical gap of patent technology ownership is large, and the development potential of some regions needs to be explored. (3) The transfer of patent technology is still dominated by enterprises, which also makes it pay more attention to the proportion of development in universities, institutions and other organizations in the future development. (4) The 
distribution of patent technology applicants in Guangdong Province is unevenly distributed, and the communication information industry is more focused. For example, the fields of home appliances, household appliances, and equipment manufacturing are relatively small, and the industrial distribution is uneven. (5) The scale of transfer of patent technology in Guangdong universities is particularly weak. Many patents cannot meet the needs of emerging markets and appear to be "sleep patents". While promoting the development of the patent transfer situation, the understanding of the advantages and importance of patent licensing needs to be strengthened, and the application of patent licensing is insufficient.

\subsection{Proposal to Promote the Transfer of Patent Technology}

In combination with China's national conditions, the specific countermeasures proposed are:

\section{1) Create a good patent authorization and technology transfer policy environment}

The government should further strengthen the protection of intellectual property rights, guide scientific and technological achievements to declare patents, encourage more patented technologies to enter the market, and it is necessary to promote patented inventions and innovations through tax reductions and exemptions. Through the implementation of measures such as the transfer of funds from special funds and other programmes to increase support for the transfer of patented technology, Establish a good technology research and development practice site, and cooperate with high-tech incubators to continuously promote the industrialization of patented technology infrastructure.

\section{2) Promote the balanced development of patent technology transfer in different regions}

Carry out comprehensive training on the training of patent technology transfer talents, Establish a group of patented technology transfer talent education bases with institutions and localities with superior resources. Actively play the role of the scientific and technological community in promoting the transfer and transformation of patent scientific and technological achievements, and promote the accurate docking of scientific and technological achievements in the demand side and the supply side.

\section{3) Pay attention to the transfer and transformation of patents in universities and research institutes}

At the same time as the enterprise-led patent technology transfer, pay attention to the transfer and transformation of patents in universities and research institutes, and at the same time strengthen the transfer of scientific and technological achievements to market-oriented services, and comprehensively promote the perfect development of patent technology transfer institutions. Enrich the role of different platform channels such as technology property rights transactions and intellectual property transactions. Vigorously develop the "Internet + Intellectual Property" program plan, set up an application platform for intellectual property databases, and promote the free distribution of patents, copyrights, trademarks and other information to achieve interconnection and mutual benefit.

\section{4) Promote more balanced patent transfer in different industries and encourage}

Promote more balanced patent transfer in different industries and encourage patent technology applicants to increase investment in household appliances and equipment manufacturing industries. In addition, it is necessary to build a team of talents for the transfer of scientific and technological achievements, and to pool and transfer scientific and technological talents to carry out the transfer and transformation of patented scientific and technological achievements, and vigorously develop the management mechanism for the transfer of talents in scientific and technological achievements. Creatively carry out the "Internet + " innovative talent service model, organize public service activities such as science and technology assistance, education and training.

\section{References}

Cao, J. G., Liu, W., Cai, W. X., Zheng, Y. P. (2009). Research on Patent Technology Transfer in IndustryUniversity-Research Cooperation. Science and Technology Management Research, (12), 488-490.

Chen, K. (2012). Analysis of the development of patents in Beijing area during the ten years of WTO accession. China Invention and Patent, (12), 64-66.

Li, W. J. (2015). Comparative Study on Regional School-enterprise Patent Cooperation Application Network: An Empirical Analysis Based on Guangdong. Modern Intelligence, (12), 106-110.

Li, Z. H., \& Ding, C. Y. (2016). Research on the Implementation Effect of the Patent Regulations of Guangdong Province. Journal of Political Science and Law, (3), 6-7.

Lin, G., Zhang, R., \& Chen, J. (2008). Analysis and Suggestions on the Status of Patent Technology Transfer in Beijing. Science, (2), 12-18.

Mao, W., Liu, C., \& Lin, W. (2013). Research on Patent Implementation and Industrialization of Chinese 
Enterprises. Science Research.

Rao, K., Meng, X. F., Andrea, P., \& Chen, W. (2011). Research on patent technology transfer in UK universities and its reference significance. China Science and Technology Forum, (2), 148-154

Song, D. L., Fu, B. H., \& Tang, H. (2011). Analysis of the transfer mode of patent technology in colleges and universities. China Science and Technology Forum, (3), 95-100.

Tang, X. X., Zhang, J. F., \& Zou, Y. Y. (2014). Research on the Status Quo of Invention Patent Application in China and Countermeasures for Improving Authorization Rate. Scientific Management Research, (1), 31-34.

Wang, Y. H., \& Wang, X. L. (2014). Analysis of the Status Quo of Patent Technology Transfer Evaluation. Software, 35(4), 71-72, 77.

Yang, L. S. (2014). Research on Patent Technology Transfer in International Technology Transfer. Industrial Technology Innovation, (2), 221-225.

Zhang, Y., Liu, B. Q., Wang, W., \& Xu, Q. X. (2013). Patent Analysis in Jiangxi Province: Strategy and Its Enlightenment. Jiangxi Science, (2), 261-269.

\section{Copyrights}

Copyright for this article is retained by the author(s), with first publication rights granted to the journal.

This is an open-access article distributed under the terms and conditions of the Creative Commons Attribution license (http://creativecommons.org/licenses/by/4.0/). 